\title{
High Strain Rate Properties of DQSK GI Steel Spot Welds
}

\author{
Abhijit Sarma, Abdelhakim Aldoshan and Sanjeev K. Khanna* \\ Mechanical \& Aerospace Engineering, University of Missouri, Columbia, Missouri, USA
}

Received: January 08, 2014; Accepted: May 05, 2014; Published: May 07, 2014

*Corresponding author: Sanjeev K Khanna, Mechanical \& Aerospace Engineering, University of Missouri, Columbia, MO 65211, Missouri, USA, Tel: 573 884 -9109; Fax: 573-884 -5090; Email: khannas@missouri.edu

\begin{abstract}
This research characterizes the high strain rate compressive loading behavior of DQSK GI steel and its spot welds using the split Hopkinson pressure bar apparatus. Such high strain rate properties of weldments are needed to evaluate the mechanical response of a spot welded structure, such as an automobile body, when subjected to dynamic loads as during a crash. The true stress-strain response of the spot welds and the parent sheet metal has been obtained by analyzing the strain history obtained from the Hopkinson bar and using the Johnson-Cook constitutive model. The findings provide an understanding of the differences between the strain rate sensitivity of the base metal and spot-welded metal. The effect of strain rate on the microstructure and microhardness of the two materials has also been examined.
\end{abstract}

\section{Introduction}

Steel is one of the most widely used metals in modern industries due to its high strength and ductility, low cost, greater design flexibility and wider spans, dimensional stability and compatibility with most manufacturing techniques [1]. There has been a significant advancement in steel industry in recent years. This advancement resulted in the development of Advanced High Strength Steel (AHSS) and High Strength Low Alloy Steel (HSLA) materials that are finding increasing use in cars, trucks, cranes, bridges, and other structures that are designed to handle high static and dynamic stresses. The combination of strength, ductility, formability, positive strain-rate sensitivity and strain hardening characteristics of AHSS and HSLA steels indicates their potential to absorb significantly higher amounts of energy during crashes than conventional low-carbon steels, while reducing the overall weight of a vehicle [2].

The mechanical behavior of materials at high strain rate is very different when compared to quasi-static (low strain rate) behavior. Usually materials are much stronger at higher rate of strain, such as caused by an impact. In recent years, the interest of researchers on high strain rate response of materials has gained momentum due to developments in various industries such as nuclear, space, military, automobile, etc. that need a better understanding of the material behavior at high strain rates to enable the proper selection of materials with desired properties [3].

In automobiles low carbon steel such as DQSK GI and AISI1020 are widely used and primarily joined by spot welding, and a typical automobile may contain about 5000 spot welds. Hence the durability of these welds is an important area for research. For this we need to know the constitutive laws of the parent metal and the welded metal, their fatigue behavior and their high strain rate behavior. In this research, we have determined the high strain rate behavior of DQSK GI spot welds and compared the results with the original base metal. The split Hopkinson pressure bar apparatus was used to investigate the high strain rate behavior of spot welds.

Although material data and joint design data is readily available under static loading conditions $[4,5]$, the information regarding the high strain rate behavior of welded joints is not so extensively available. There are very few references [6-8] that can be found in open sources on high strain data on spot welded joints. This lack of available data has resulted in the ignorance of the differences in the dynamic strength of the base and weld materials. In many finite element models and other analysis, the weld is considered as having the same material properties as the base metal.

The main interest in our investigation is to compare dynamic strength of DQSK GI steel base metal with the spot weld metal under high strain rate loading conditions. The dynamic strength can be derived from the stress strain curves at different strain rates. There are many experimental techniques to investigate dynamic properties of material under high strain rate like drop weight and pendulum tester, servo-hydraulic test instruments, split Hopkinson bar, but split Hopkinson bar is the most widely used and most convenient of all.

The Hopkinson bar experimental technique finds its origin in the pioneering efforts of John Hopkinson (1872) and later his son, Bertram Hopkinson [9] from 1905 to 1914, who sought to experimentally establish the dynamic strength of metal wires. Much later an important contribution was made by Kolsky [10] in 1949, who added a second pressure bar to Hopkinson's 
original apparatus (single bar) swith the specimen sandwiched in between, and hence the name split Hopkinson bar. Kolsky measured the stress profiles in both bars, and related these to the stress-strain history of the sample, through a onedimensional elastic wave analysis. The modification has been universally adopted by the mechanics community. Because of this contribution split Hopkinson bar is also sometime referred to as Kolsky bar.

Another important contributor to the development of split Hopkinson bar includes Rand and Jackson [11] in 1967. They demonstrated analytically that although the presence of axial inertia does cause non-uniform distribution of stresses, strain and rate of strain, averaging the recorded strains result in a reasonable approximation of the actual stress-strain relation. They also showed that the effects of friction and radial inertia are negligible. Another important contribution was from Hauser and Hauser [12] . They added strain gages to the split Hopkinson bar to measure surface strains.

Split Hopkinson bar has been widely used and modified to determine the dynamic properties of a variety of engineering materials, such as metals [13], concrete [14, 15], ceramics [16-18], and hard polymers [19]. The dynamic deformation characteristics of many steels have been extensively studied for military or engineering applications.

Spot welds are one of the main joining systems used for the assembly of steel car components. Robin et al. [20] have studied the performance of spot welds under the influence of high strain rate loading, such as those encountered under crash conditions. They have developed the finite element simulation of the resistance welding to establish a micro-mechanical model that can be used to perform fracture analyses of spot welds. Wang and $\mathrm{Lu}$ [21] have conducted an experimental study to investigate the dynamic strength of spot welds under high strain rate loadings. They have obtained the flow stresses of both base steel material and weld under strain rate loading of $9 \times 10^{2} \mathrm{~s}^{-1}$. They found that both the base and weld metals are very much dependent on the strain rate and weld is more dependent on strain rate than the base metal.

High strain rate analysis on DQSK GI steel and other steels for automotive applications was done by Cady et al. [22]. However, they only studied discrete strain rates of $0.001 \mathrm{~s}^{-1}, 0.1 \mathrm{~s}^{-1}, 50 \mathrm{~s}^{-1}$ and $3500 \mathrm{~s}^{-1}$. Their work includes the determination of constants of constitutive models using results from mechanical tests. Cady et al. observed inhomogeneity in the mechanical properties of DQSK GI steel throughout the thickness, which was attributed to the temper rolling. This results in a layered composite behavior of DQSK GI steel that makes its surface hard and its center layer soft.

Effect of increasing strain rate from low to high strain rates at room temperature on DQSK GI steel was presented by Cady et al. [23]. They tested DQSK GI steel at different strain rates ranging from low strain rates $\left(0.1 \mathrm{~s}^{-1}\right)$ to high strain rates up to $3500 \mathrm{~s}^{-1}$ They observed that as strain rate increases, yield stress and flow stress levels increase as well. However, work hardening rate drops as strain rate increases. This drop is attributed to adiabatic heating effect at high strain rates. Also, decrease in strain hardening may be partially due to deformation twins formation and dislocation storage increase in individual grains. This Continuous drop of strain hardening is a typical response of work hardening of bcc metals [24]. Dietenberger et al. [25] conducted high strain rate test on DQSK GI steel. Similarly, strain rate sensitivity is shown in their work in which yield stress increases as strain rate increases from low to high strain rates. They numerically modeled a vehicle crash over a range of high strain rates using DQSK GI steel. DQSK GI displayed similar results compared to High Strength Low Alloy (HSLA). In general literature, studies on the effect of mechanical properties of DQSK GI steel at high strain rates are limited.

The objective of the present research was to analyze the high strain rate mechanical response of DQSK GI steels and compare mechanical properties of the base metal with the spot-welded region. We have also determined the Johnson-Cook strength model constants for DQSK GI parent metal and the spot-weld to compare the strain sensitivity and strain rate sensitivity of base metal and weld metal region.

\section{Introduction to Spot Welding and High Strain Rate Testing}

Spot Welding: Spot welding or resistance spot welding involves the joining of two or more pieces of sheet metal in localized areas or spots where melting and coalescence of a small volume of material occurs from heating caused by resistance to the passage of an electric current. This process is typically used to obtain a lap joint of sheet metal parts of thickness 0.125 in. (3 $\mathrm{mm}$ ) or less, using a series of spot welds, in situations where an airtight assembly is not required. It is widely used in the mass production of automobiles, where a typical automobile may contain more than 5000 spot welds [26].

Split Hopkinson Pressure Bar Apparatus: Split Hopkinson pressure bar is mostly used in the range of $10^{2}$ to $10^{4} \mathrm{sec}^{-1}$ strain rate. In recent years, with the help of significant advancement in data acquisition techniques, Hopkinson bar test technique has led to significant advances in high strain rate testing capabilities [27] . The classical split Hopkinson bar consists of two elastic bars, called incident and transmission bar that sandwich a short cylindrical specimen between them and a dynamic loading device, usually a gas gun that propels a striker bar. Upon firing from the gas gun, the striker bar impacts the incident bar and a rectangular compression wave of well-defined amplitude and length is generated in the incident bar. The length or duration of the compressive pulse generated in the incident bar is twice the wave-transit time in the striker bar and the magnitude is directly proportional to the striker velocity. The compressive stress wave generated in the incident bar travels towards the specimen and from the specimen it partially reflects as a tension pulse back into the incident bar. The portion of the incident wave transmitted through the specimen to the transmission bar as a compression wave depends on the relative acoustic impedance of the specimen and transmission bar. Strain gages mounted on the incident and transmission bar measure the strain in the two bars. Specimen 
stress in measured by using the strain from the transmission bar. Specimen strain can be determined by analyzing the strain rate in the incident bar. By monitoring and analyzing the strains in the two bars, specimen stress-strain properties are determined. Figure 1 shows the typical arrangement of a split Hopkinson bar.

The equations for determining the stress-strain response of a material in a compression split Hopkinson bar are based on the following assumptions:

1. Stresses and velocities at the end of the specimen are propagated down the bar in an undispersed manner.

2. Wave transit time in the specimen is much smaller compared to the total time of the test. This requirement necessitates a short specimen length.

3. Stress and strain are assumed to be uniform over the length of the specimen.

The stress and strain and strain rate in the specimen are obtained from the following relations. The strain in the specimen, $\varepsilon_{\mathrm{s}}$, is given by

$$
\varepsilon_{S}=\frac{-2 c}{L} \int_{0}^{t} \varepsilon_{r}(t) d t
$$

Where $\mathrm{c}$ is the speed of sound in the bar, $\mathrm{L}$ is the thickness of the specimen, $\varepsilon_{r}$ is the strain due to the reflected wave in the incident bar.

The specimen stress, $\sigma_{\mathrm{s}}$, is obtained from the equation

$\sigma_{s}=\frac{E A}{A_{s}} \varepsilon_{t}$

Where $\mathrm{A}$ is the area of cross section of the bar, $\mathrm{A}_{\mathrm{s}}$ is the area of cross section of the specimen, $\varepsilon_{t}$, is the strain due to the transmitted wave in the transmitter bar.

While the strain rate in the specimen, $\dot{\varepsilon}_{s}$, is given by the relation

$$
\dot{\varepsilon}_{S}=\frac{-2 c}{L} \varepsilon_{r}
$$

The condition for ensuring dynamic stress equilibrium in the specimen is shown below.

$$
\varepsilon_{t}=\varepsilon_{i}+\varepsilon_{r}
$$

Many testing conditions greatly affect the implementation and effectiveness of equations (1-4). For instance the duration of the impact pulse determines how much the specimen may be deformed. The fundamental assumption that the specimen deforms uniformly and dynamic stress equilibrium in the

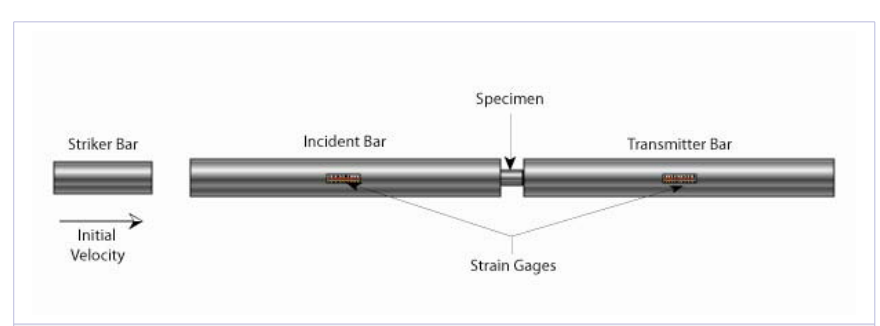

Figure 1: Schematic of a split Hopkinson bar. specimen is achieved must be enforced by lubricating the specimen-pressure bar interfaces and choosing appropriate specimen dimensions. By carefully addressing these issues, dynamic stress-strain relations can be obtained for a broad range of materials using above equations. The review article by Gama, et al. [28] clearly details many aspects of experiments and analysis related to SHPB; and was used as the basis in this study.

\section{Experimental Setup}

The SHPB apparatus has the following major assemblies/ components and some of these are briefly described below.

1 Pressure Bar Assembly

2 Gas Gun Assembly

3 Strain Gages

4 Data Acquisition System

5 Damping System

The pressure bar assembly consists of a striker bar, incident bar and the transmitter bar. The pressure bars are usually made of high strength steel. We have used maraging steel for the pressure bars which has a yield strength of over $1400 \mathrm{MPa}$ and ultimate tensile strength of over $1800 \mathrm{MPa}$. We have used two striker bars, the shorter one was 6 inch in length and the longer one was 12 inch in length, as shown in Figure 2. The duration of the pulses depends on the length of the striker bar, and depending on the need either one could be used.

The incident bar used in this investigation was 72 inches long and the transmitter bar was 54 inches long. The diameters of the bars are 0.5 inch. Hence the length-to-diameter ratio is much more than twenty. The faces of all bars were ground flat and parallel and the blocks supporting the incident and transmitter bar contain circular bush bearings for free movement and alignment. Alignment was checked by verifying that each pressure bar translates and rotates freely through the mounting brackets and that the faces of the incident and the transmitter bars meet identically when brought together without any specimen in between. Another way of checking alignment is to record the strain data from the strain gages placed on diametrically opposite sides of the pressure bar and compare for any bending of the bar. Any significant difference in the two strain outputs indicates bending in the concerned bar.

Strain gage is the most commonly used device for measuring strain in SHPB. In this technique two strain gages are mounted at diametrically opposite positions on each bar and connected so as to average out any strain due to bending of the bars. Although standard strain gage technology is used the main difficulty has been the development of techniques to attach lead wires to the strain gages. These lead wires experience large accelerations and can easily break when the stress wave passes.

Figure 3 shows the strain gage installation on a 0.5 inch diameter pressure bar. In this research $350 \Omega$ strain gages of 0.0625 in $(0.15 \mathrm{~mm})$ gage length were used. The instrumentation and data acquisition required for the split Hopkinson bar includes 


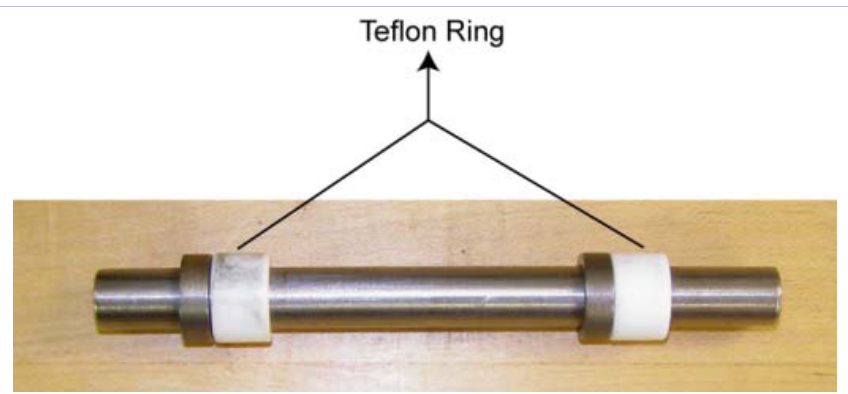

Figure 2: A view of the striker bars.

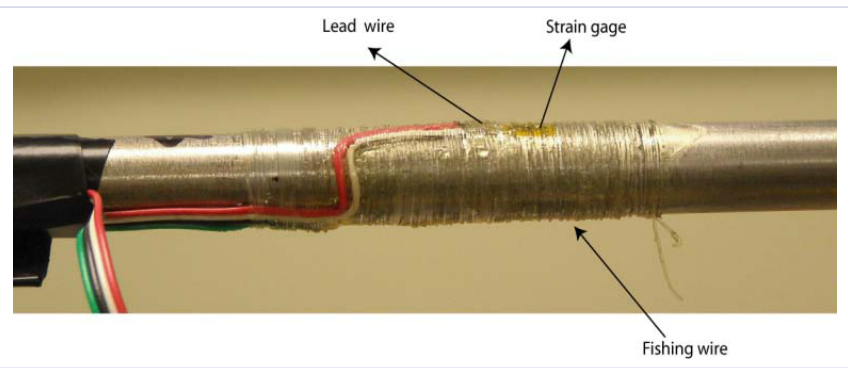

Figure 3: Strain gage installation on a 0.5 inch diameter pressure bar.

two strain gage signal conditioners and a means of recording these signals. The strain gage signal conditioner must have a frequency response of greater than or equal to $1 \mathrm{MHz}$. Also the low voltage signals from the strain gages must be amplified to match the dynamic range of oscilloscope. Once amplified, a digital oscilloscope records the strain signals.

Schematic of the damping system is as shown in Figure 4. The front end of the damper is filled with lead, because of its softness. When the pressure bar hit the damper upon firing it first hits the lead and then it is brought to a stop by three springs in series placed inside the damper.

\section{Results and Discussion}

The details of the high strain rate tests done both on the spot weld and the base metal are presented in this section. The mechanical properties of DQSK GI under impact loading have been evaluated by plotting stress vs. strain as a function of strain rate. Then these results are analyzed to get the yield point vs. strain rate plot. The methodology used to determine Johnson Cook constitutive model constants for predicting material behavior for DQSK GI steel, both for the spot weld and base metal is provided. By determining these constants one can compare the work hardening and strain rate sensitivity of both base metal and weld metal regions. Also microhardness and microstructure of the samples are reported both before and after impact tests at different strain rates. The samples used were discs of $6.0 \mathrm{~mm}$ diameter and $1.5 \mathrm{~mm}$ thickness. A spot weld disc cutter was used to cut out spot weld samples from the welded coupons.

\section{Stress-strain response}

Figure 5 compares the three pulses, incident, transmitted and reflected, together by shifting the pulses to the same starting point. The main difficulty is to shift the three waves with good accuracy. This shifting is needed as the signal at the incident bar is recorded prior to wave reaching the bar and specimen interface and the transmitter signal is recorded after the wave cross this interface. The start of each pulse has to be identified properly to accurately construct the dynamic stress-strain plot. When each strain signal was more (for reflected strain signal) or less (for incident and transmitted strain signal) than $0 \mu \mathrm{m} / \mu \mathrm{m}$, we considered that as the start for that specific strain signal.

Once the strain signal is attained it is checked for dynamic equilibrium which is given by the condition below:

$$
\varepsilon_{I}(t)+\varepsilon_{R}(t)=\varepsilon_{T}(t)
$$

where, $\varepsilon_{I}$ is the incident strain history, $\varepsilon_{R}$ is the reflected strain history and $\varepsilon_{T}$ is the transmitted strain history.

The strain signal measured on the incident and transmitter bar were converted into strain and stress values in the specimen by using equations (1-3).

\section{Stress-strain Response of DQSK GI Base Metal}

A range of strain rates from 650 to $2400 \mathrm{~s}^{-1}$ were investigated and some typical stress-strain responses are provided below in Figure 6. The stress-strain plots were analyzed to obtain the yield
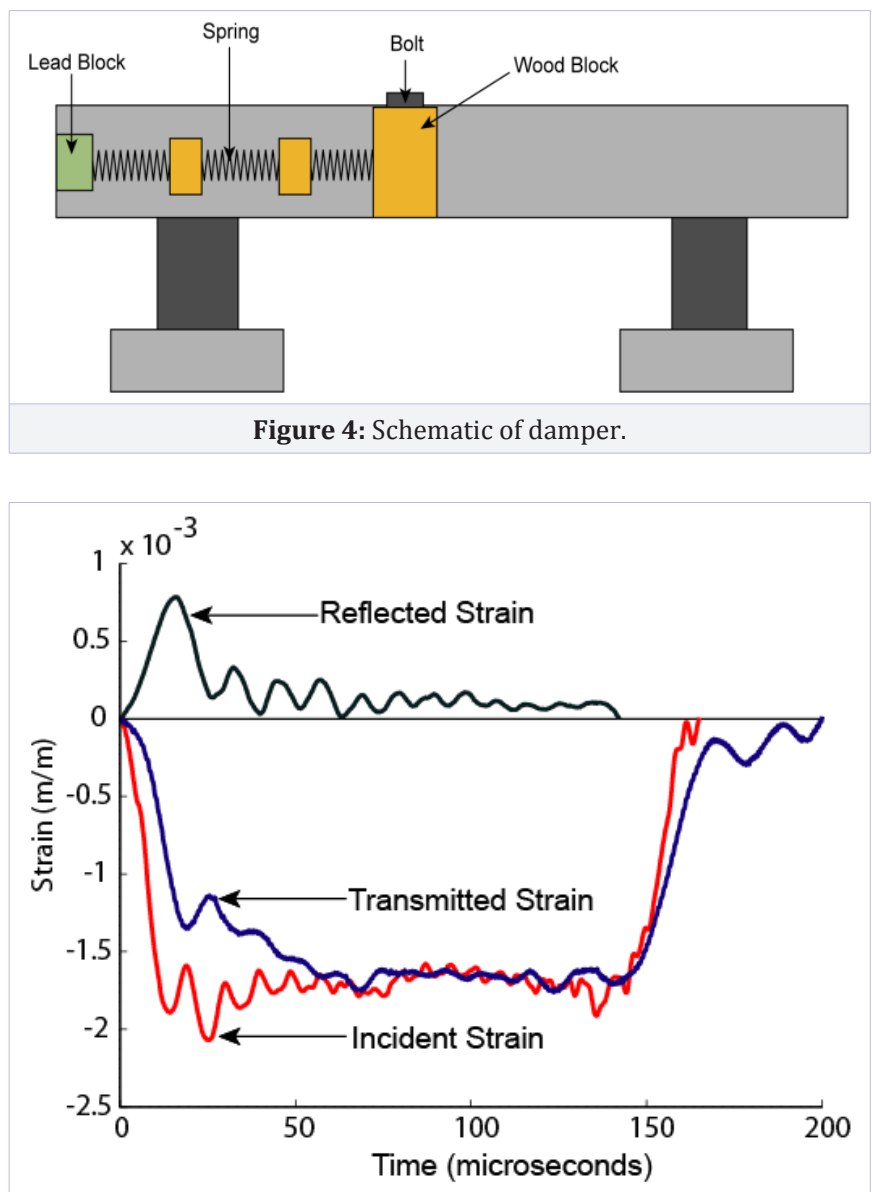

Figure 5: Three strains displayed together to show their relative magnitude and sign. 
strength of the materials under various strain rates. As shown in Figures 6 a through $6 \mathrm{~d}$, a fall-off (drop) region is observed which is believed to be a result of adiabatic heating effects [23].

These stress-strain data were again used for determining the Johnson-Cook (JC) constitutive model constants. The method for obtaining JC constants from stress-strain plots are explained in a later section.

\section{Stress-strain Response of DQSK GI Weld Metal}

A range of strain rates from 300 to $2250 \mathrm{~s}^{-1}$ were investigated and some typical stress-strain responses are shown in Figure 7.

\section{Yield Strength as a Function of Strain Rate}

As shown in Figure 8, dynamic loading results in an increase in the yield strength of the base metal and weld metal with strain rate.

\section{Johnson-Cook Constitutive Model}

Dynamic events often involve high strain rate. To accurately predict the dynamic response of a material, the high strain rate effects on flow stress must be determined. Towards this end the Johnson-Cook (J-C) constitutive model has been used [29-31]. The J-C empirical model describes the Von Mises flow stress $Y$ of a material as a function of strain (work) hardening, strain rate hardening and thermal softening. The Johnson Cook strength model is a given by:

$$
Y=A\left(1+\frac{B}{A} \varepsilon^{n}\right)\left(1+C \ln \varepsilon^{*}\right)\left(1-T^{* m}\right)
$$

Where, $\varepsilon$ is the equivalent plastic strain, $\varepsilon^{*}$ is the strain rate nondimensionalized by the reference strain rate of $1 \mathrm{sec}^{-1}, T^{* m}$ is the nondimensionalized temperature and $\mathrm{A}, \mathrm{B}, \mathrm{C}$ and exponent $\mathrm{n}$, $\mathrm{m}$, are five material constants. The constant $A$ is the yield stress corresponding to a plastic strain rate of $\varepsilon=1 \mathrm{sec}^{-1}$ and at room temperature. The first term in equation (5) represents the work hardening response of the material at the reference strain rate, while the second term represents the strain rate sensitivity and the third term accounts for the temperature sensitivity.

$$
\begin{aligned}
& T^{* m} \text { is given by: } \\
& T^{* m}=\frac{T-T_{r}}{T_{m}-T_{r}}
\end{aligned}
$$

Where, $T_{r}$ is room temperature and $T_{m}$ is the melting temperature of the material. If the experiment is carried out at room temperature i.e. at $\mathrm{T}=T_{r}$, equation (5) reduces to:

$$
Y=A\left(1+\frac{B}{A} \varepsilon^{n}\right)\left(1+C \ln \varepsilon^{*}\right)
$$

All the experiments in this study were conducted at room temperature. Thus, equation (7) was used to calculate the Johnson Cook constants for each material. The steps involved in calculating the JC constants are explained in the following sections.

\section{JC Constants of DQSK GI Base Metal}

The experimentally obtained stress-strain plots at various
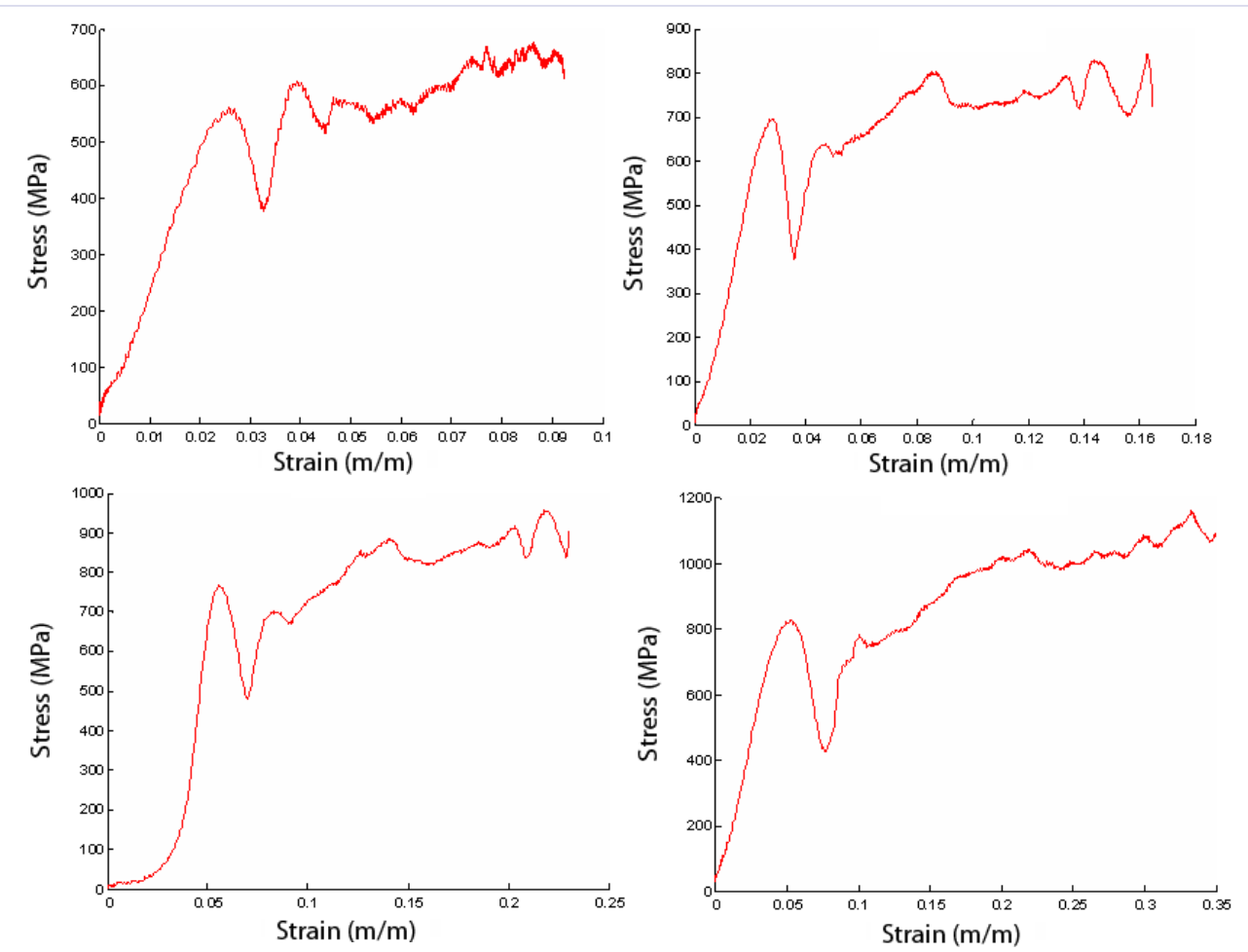

Figure 6: Stress vs. strain of DQSK GI base metal at a strain rate of: (a) $650 \mathrm{~s}^{-1}$, (b) $1100 \mathrm{~s}^{-1}$, (c) $1500 \mathrm{~s}^{-1}$, and (d) $2400 \mathrm{~s}^{-1}$. 

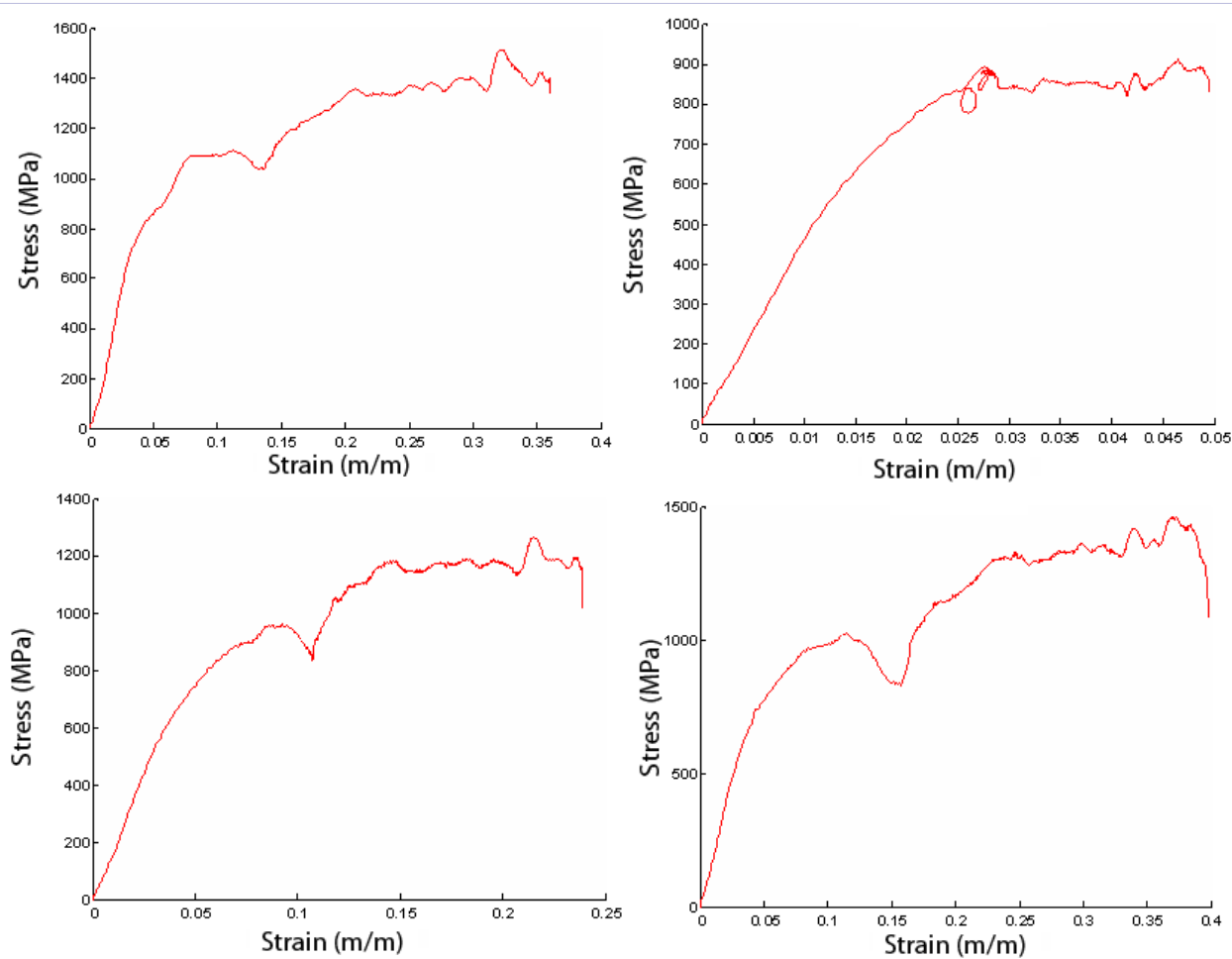

Figure 7: Stress vs. strain of DQSK GI weld metal at a strain rate of: (a) $250 \mathrm{~s}^{-1}$, (b) $1300 \mathrm{~s}^{-1}$, (c) $2000 \mathrm{~s}^{-1}$, and (d) $2250 \mathrm{~s}^{-1}$.

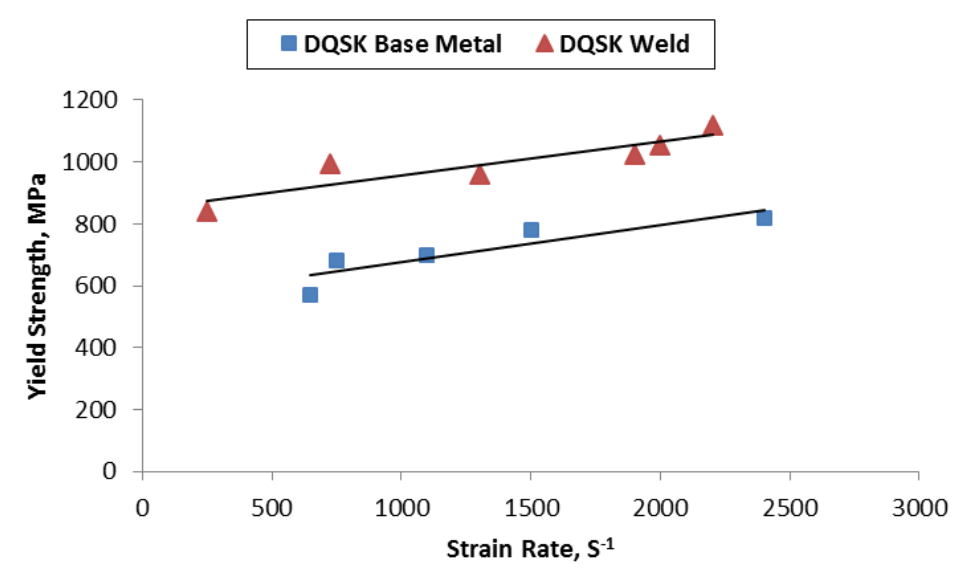

Figure 8: Yield Strength vs. Strain Rate for DQSK GI Base Metal and DQSK GI Weld.

strain rates were used to determine the J-C constitutive model constants. The plastic portion of the experimental stress-strain plots have been plotted by fitting a smooth exponential curve of the form $y=\beta x^{\alpha}$, as shown below in Figure 9. The SHPB was used to generate data at high strain rates $\left(650\right.$ to $\left.2400 \mathrm{~s}^{-1}\right)$ while low strain rate data $\left(0.005 \mathrm{~s}^{-1}, 0.1 \mathrm{~s}^{-1}\right.$ and $\left.10 \mathrm{~s}^{-1}\right)$ was obtained from Ford Motor Co. These data are shown in tabular form in Table 1.

The plot of $\beta$ vs. strain rate and $\alpha$ vs. strain rate can be interpolated to generate a function describing the behavior of
DQSK GI base metal at a strain rate of $1 \mathrm{~s}^{-1}$. The resulting function is:

$$
y=900 \varepsilon^{0.14}=\beta \varepsilon^{\alpha}
$$

Determination of J-C Constant A: Constant A is the value of the yield stress corresponding to an offset strain of $0.2 \%$ or 0.002 at $1 \mathrm{~s}^{-1}$ strain rate. As we did not have DQSK GI base metal data under static loading, we used the yield strength data of 1020 steel (it has almost same composition as DQSK GI) given by Haggag and Bell [32]. 
DQSK GI base metal constant $A$ corresponding to a strain rate of 1 (one) $\mathrm{s}^{-1}$ was found to be $225 \mathrm{MPa}$.

Determination of J-C Constants B and $\mathbf{n}$ : Constants B and $n$ were obtained by applying the least square technique to the data in Table 1 as explained by Sarma [33].

The following results for DQSK GI base metal were obtained: $\mathrm{B}=997.95 \mathrm{MPa}$, and $\mathrm{n}=0.87932$.

Determination of J-C Constant C: Using the methods of analysis outlined by Sarma [33] the value of $C$ was found to be: $\mathrm{C}=0.09334$.

For DQSK GI sheet steel the Johnson-Cook constitutive model representing plastic flow can be written using constants $\mathrm{A}, \mathrm{B}, \mathrm{C}$ and $\mathrm{n}$ as:

$$
Y(M P a)=\left(225+(997.95) \varepsilon^{(0.87932)}\right)\left(1+(0.09334) \ln \varepsilon^{*}\right)
$$

\section{JC Constants of DQSK GI Spot-welded Metal}

The analysis for determining the Johnson-Cook constants of spot-weld metal was carried out in a way similar to that for the base metal described above. The experimentally obtained stressstrain plots at various strain rates were used to determine the J-C constitutive model constants. The SHPB was used to generate data at high strain rates (250 to $2200 \mathrm{~s}^{-1}$ ) while low strain rate data $\left(0.15 \mathrm{~s}^{-1}\right)$ was obtained from a tensile test. These data are shown in Table 2.

The plots of $\beta$ vs. strain rate and $\alpha$ vs. strain rate were plotted as a function of strain rate using data shown in Table 2 and interpolated to generate a function describing the behavior of DQSK GI weld metal at a strain rate of $1 \mathrm{~s}^{-1}$. The resulting

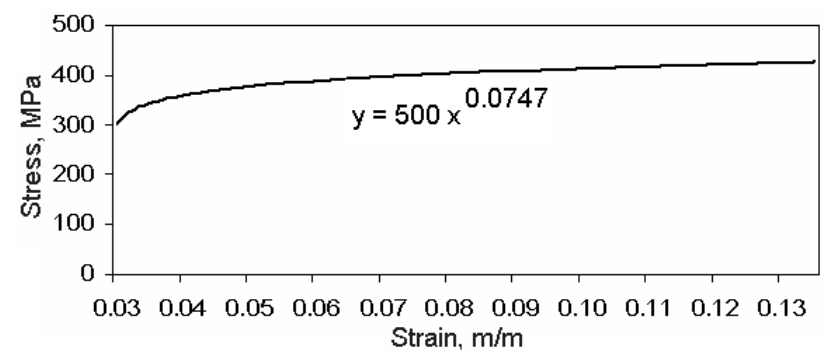

Figure 9: Plastic stress-strain behavior of DQSK GI base at strain rate $0.005 \mathrm{~s}^{-1}$.

Table 1: Dynamic Strength Data of DQSK GI Base Metal.

\begin{tabular}{|c|l|l|l|}
\hline Strain Rate & Function, $\mathrm{y}=\beta \varepsilon^{\alpha}$ & $\beta$ & $\alpha$ \\
\hline 0.15 & $\mathrm{y}=500 \varepsilon^{0.0747}$ & 500 & 0.0747 \\
\hline 650 & $\mathrm{y}=750^{\varepsilon_{s}=\frac{-2 c}{L} \xi_{\varepsilon_{f}(t) t t}}$ & 750 & 0.0624 \\
\hline 750 & $\mathrm{y}=855 \varepsilon^{0.0679}$ & 855 & 0.0679 \\
\hline 1100 & $\mathrm{y}=900 \varepsilon^{0.0629}$ & 900 & 0.0629 \\
\hline 1500 & $\mathrm{y}=1045 \varepsilon^{0.084}$ & 1045 & 0.084 \\
\hline 2400 & $\mathrm{y}=1280 \varepsilon^{0.116}$ & 1280 & 0.116 \\
\hline
\end{tabular}

Table 2: Dynamic Strength of DQSK GI Weld Metal.

\begin{tabular}{|c|l|l|l|}
\hline Strain Rate & Function, $\mathrm{y}=\beta \varepsilon^{\alpha}$ & $\beta$ & $\alpha$ \\
\hline 0.15 & $\mathrm{y}=500 \varepsilon^{0.0747}$ & 500 & 0.0747 \\
\hline 250 & $\mathrm{y}=980 \varepsilon^{0.0525}$ & 980 & 0.0525 \\
\hline 725 & $\mathrm{y}=1170 \varepsilon^{0.0679}$ & 1170 & 0.0416 \\
\hline 1300 & $\mathrm{y}=1320 \varepsilon^{0.0629}$ & 1320 & 0.0871 \\
\hline 1900 & $\mathrm{y}=1450 \varepsilon^{0.084}$ & 1450 & 0.0974 \\
\hline 2200 & $\mathrm{y}=1550 \varepsilon^{0.116}$ & 1550 & 0.08 \\
\hline
\end{tabular}

function is:

$$
y=800 \varepsilon^{0.07}
$$

Similar to the process followed for base metal, the DQSK GI weld metal J-C constants were obtained as:

$$
\mathrm{A}=386 \mathrm{MPa}, \mathrm{B}=998.452 \mathrm{MPa}, \mathrm{n}=0.8182 \text {, and } \mathrm{C}=0.143 \text {. }
$$

For DQSK GI spot-weld steel the Johnson-Cook constitutive model representing plastic flow can be written using constants $\mathrm{A}, \mathrm{B}, \mathrm{C}$ and $\mathrm{n}$ as:

$$
Y(M P a)=\left(386+(998.452) \varepsilon^{(0.8182)}\right)\left(1+(0.143) \ln \varepsilon^{*}\right)
$$

From the results, it is clear that the work hardening effect constant B is nearly the same for both DQSK GI base and weld metals; this indicates a similar yielding behavior. However, $\mathrm{n}$ is higher for DQSK GI base than DQSK GI weld metal leading to higher strain hardening. And the strain rate sensitivity constant C for DQSK GI base metal is higher than that of DQSK GI welds metal.

The values of Johnson-Cook (JC) constants obtained in this investigation are different from the referenced studies. The possible reasons are the difference in composition, microstructure, different sample sizes used and different processing/strain history. However, the yield stress results of DQSK base metal are relatively comparable to previous work done at high strain rate condition.

\section{Microhardness Measurements}

The Vickers microhardness of the samples was measured after the impact tests using a Buehler Micromet series microhardness tester. Microhardness tests were conducted along the centerline of the specimen using a Vickers pyramidal indenter at a load of $300 \mathrm{~g}$ and dwell time of $20 \mathrm{~s}$. All hardness tests were performed at room temperature of approximately $22^{\circ} \mathrm{C}$.

\section{DQSK GI Steel}

The micro hardness of all materials we had tested exhibits a similar trend, that is, the hardness value increases with the 
impact strain rate, as shown in Figure 10 and Figure 11 for DQSK GI base metal and weld metal, respectively. Higher dynamic strain rate resulted in higher hardness.

From the above figures, we could observe that at zero strain rate or prior to any impact test, the hardness number of DQSK GI weld metal is more than the hardness number of DQSK GI base metal. The hardness value increases with the impact strain rate for both base and weld metals. This is due to the work hardening of the material, under impact loading which produces a large permanent plastic strain. It is observed that the hardness value follows the same trend that we had observed in case of yield strength vs. strain rate plot of DQSK GI weld and base metal.

It should be noted that in our weld samples used for impact tests did not include the heat affected zone (HAZ). 6 mm diameter discs were cut from center of spot so as not to include any portion of the circumferential notch which would introduce a gap in the two sheets and adversely affect the experimental results.

\section{Microstructure Analysis}

The variations in microstructure of a material strongly influence its flow behavior during deformation. The microstructure of the impacted specimens was investigated using an optical microscope and was compared with the microstructure of as received metal without impact loading. The specimens were polished with a 400 grit silicon carbide paper followed by a 5 micron and then 0.2 micron diamond paste on a polishing cloth, and then etched with $2 \%$ nital solution $\left(2 \mathrm{~mL} \mathrm{HNO}_{3}\right.$ and $98 \mathrm{~mL}$ alcohol) for about 2 minutes.

\section{DQSK GI Base Metal}

Figure 12a shows the microstructure of DQSK GI base material without impact loading. Microstructures of DQSK GI base metal at strain rates of $1100 \mathrm{~s}^{-1}$ and $2400 \mathrm{~s}^{-1}$ are shown in Figures $12 \mathrm{~b}$ and 12c. From Figure 12a, the base metal of the DQSK GI steel has a microstructure consisting of coarse ferrite grains with a dispersion of pearlite grains.

At moderate strain rates of about $1100 \mathrm{~s}^{-1}$, we could observe

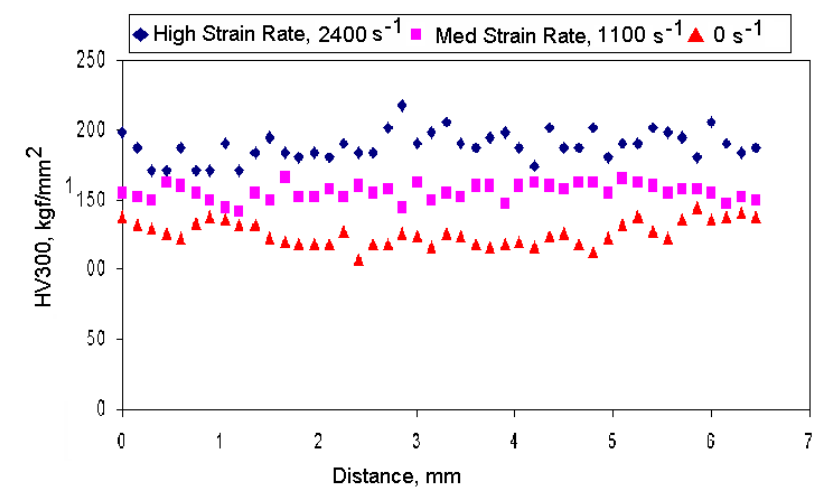

Figure 10: Microhardness distribution in DQSK GI base metal.

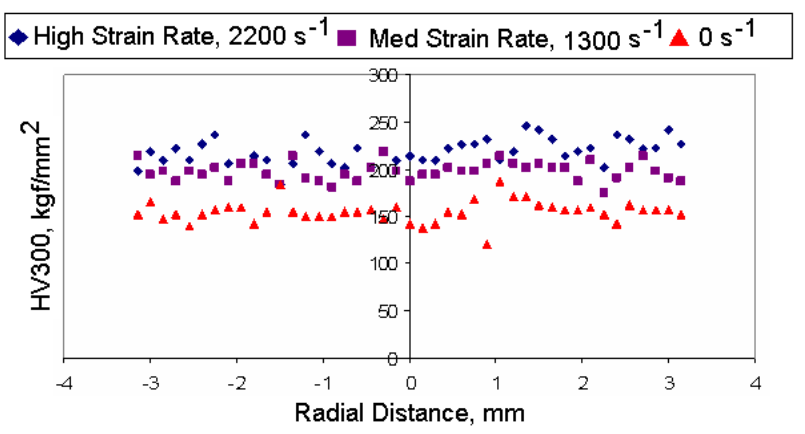

Figure 11: Microhardness distribution in DQSK GI spot weld across the diameter.

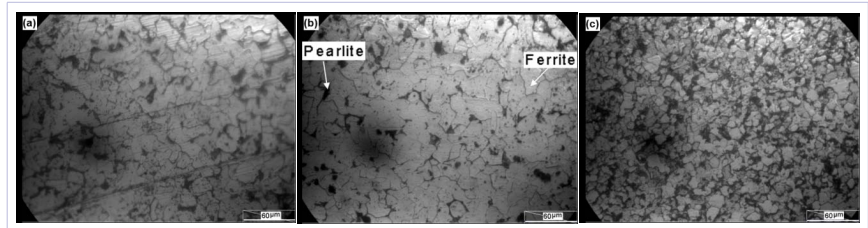

Figure 12: Microstructure of DQSK GI base metal: (a) $0 \mathrm{~s}^{-1}$, (b) $1100 \mathrm{~s}^{-1}$, and (c) $2400 \mathrm{~s}^{-1}$.

no effect of strain rates on microstructure. From Figure 12c it can be seen that the size of the ferritic grain matrix decreases with increasing strain rate, but the portion of pearlite increases with increasing strain rate. This reduction in area of ferrite and increase in area of pearlite is possibly due to the plastic deformation of about $30 \%$ and could lead to an increase in the flow stress due to the enhancement of the grain boundary area and increase in the harder pearlite phase. These effects are more pronounced at higher strain rate $\left(2400 \mathrm{~s}^{-1}\right.$ and higher). This suggests that a very high strain rate loading prompts extensive flow localization, which results in a high degree of inhomogeneous deformation within the grain. We do not expect increase in hardness due to re-crystallization.

\section{DQSK GI Spot weld metal}

Figure 13a shows the microstructure of DQSK GI weld material without impact loading. Microstructures of DQSK GI weld metal at strain rates of $1300 \mathrm{~s}^{-1}$ and $2200 \mathrm{~s}^{-1}$ are shown in Figures 13b and 13c. From Figure 13a, the base metal of the DQSK GI steel has a microstructure similar to that of the as-received DQSK sheet metal. .

For DQSK GI weld it is observed that strain rate has no or very little effect on the ferritic grain size and the portion of pearlite. It is almost same at all strain rates. It may need higher strain rate than we had achieved to observe any difference in the microstructure.

\section{Summary}

1) In the test range under study, it is found out that strain rate sensitivity increases with increasing strain rate for DQSK GI weld and base metal. It is clear that as strain rate increases the yield strength also increases regardless of the material tested 


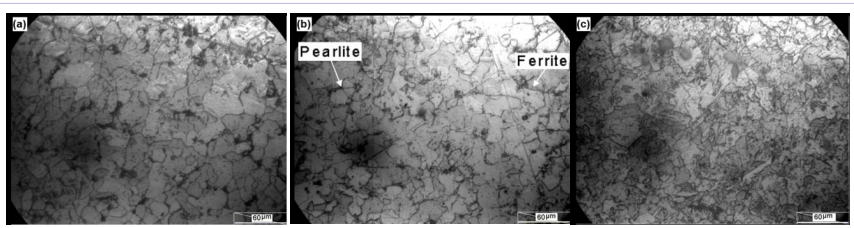

Figure 13: Microstructure of DQSK GI weld metal: (a) $0 \mathrm{~s}^{-1}$, (b) $1300 \mathrm{~s}^{-1}$, and (c) $2200 \mathrm{~s}^{-1}$

2) From the microstructure study of both the material under different loading conditions, it is found out that the size of the ferritic grain matrix decreases with increasing strain rate for DQSK GI base material. For DQSK GI the amount of pearlite increases with increasing strain rate. This reduction in ferrite size and increase in pearlite phase leads to an increase of the flow stress due to the enhancement of the grain boundary area thus increasing the hardness of the material at high strain rate. There is minimal change in the size of ferritic grain matrix for DQSK GI weld in the range of strain rates obtained in this study. Also there is no change in the amount of pearlite for DQSK GI weld.

3) The hardness measurements suggest that the dynamic loading increased the hardness of the weld and base metal and, accordingly, the yield stress. This is due to the work hardening of the material, which produced further permanent plastic strain. Thus higher dynamic strain rate implies higher hardness number.

4) The J-C constitutive model constants A, B, n and C for DQSK GI steel base metal and weld were determined. The resulting Johnson Cook constitutive model for the spotwelded and as-received DQSK steel is as follows:

DQSK GI Weld:

$Y(M P a)=\left(386+(998.452) \varepsilon^{(0.8182)}\right)\left(1+(0.143) \ln \varepsilon^{*}\right)$

DQSK GI Steel:

$Y(M P a)=\left(225+(997.95) \varepsilon^{(0.87932)}\right)\left(1+(0.09334) \ln \varepsilon^{*}\right)$

The base metal is more strain rate sensitive compared to the weld metal.

\section{References}

1. Hogan BJ (1978) Manufacturing Engineering.

2. Simunovic S, Shaw J, Aramayo GA (2000) Material modeling effects on impact deformation of ultralight steel auto body. Society of Automotive Engineers: Warrendale Pa.

3. Panic N (1999) High strain rate induced failure in steels at high shear strains. University of Manitoba.

4. Tweeddale J (1964) The Mechanical Properties of Metals: Assessment and Significance: Allen \& Unwin.

5. Llewellyn D, Hudd R (1998) Steels: Metallurgy and applications. (3 $3^{\text {rd }}$ ed.) Oxford: Butterworth-Heinemann.

6. Yan B, Urban D (2003) Characterization of fatigue and crash performance of new generation high strength steels for automotive applications. In:
AISI/DOE technology roadmap program: p. 2-8.

7. Xu K, Wong C, Yan B, Zhu H (2003) A High Strain Rate Constitutive Model for High Strength Steels. SAE Technical Paper.

8. Yan B, Xu K (2002) High Strain Rate Behavior of Advanced High Strength Steels for Automotive Applications. Proceedings of 44th Metal Working and Steel Processing Conference.

9. Hopkinson B (1914) A Method of Measuring the Pressure Produced in the Detonation of High Explosives or by the Impact of Bullets. Philosophical Transactions of the Royal Society of London. P.213- 437.

10. Kolsky H (1949) An Investigation of the Mechanical Properties of Materials at very High Rates of Loading. Proceedings of the Physical Society Section B. $62(11)$ : p. 676

11. Jackson JW, Rand JL (1967) The split Hopkinson pressure bar (Split Hopkinson pressure bar technique for determining stress-strain relation in aluminum). New York: Gordon and Breach.

12. Dharan CKH, Hauser FE (1970) Determination of stress-strain characteristics at very high strain rates. Experimental Mechanics. 10(9): p. $370-376$

13. Gray GT (2000) Classic Split-Hopkinson Pressure Bar Testing. Metals Handbook, American Society for Metals, Materials Park, Ohio. 8: p. 462476.

14. Grote DL, Park SW, Zhou M (2001) Dynamic behavior of concrete at high strain rates and pressures: I. experimental characterization. International Journal of Impact Engineering. 25(9): p. 869-886.

15. Ross CA, Jerome DM, Tedesco JW, Hughes ML (1996) Moisture and Strain Rate Effect on Concrete Strength. American Concrete Institute Journal. 93: p. 293-300.

16. Chen W, Ravichandran G (1996) Static and Dynamic Compressive Behavior of Aluminum Nitride under Moderate Confinement. Journal of the American Ceramic Society. 79(3): p. 579-584.

17. Chen W, Ravichandran G (1997) Dynamic compressive failure of a glass ceramic under lateral confinement. Journal of the Mechanics and Physics of Solids. 45(8): p. 1303-1328.

18. Chen W, Ravichandran G (2000) Failure mode transition in ceramics under dynamic multiaxial compression. International Journal of Fracture. 2000. 101(1-2): p. 141-159.

19. Walley SM, Field JE, Safford NA (1989) A Study of the Rapid Deformation Behaviour of a Range of Polymers. Philosophical Transactions of the Royal Society of London. Series A, Mathematical and Physical Sciences. 328(1597): p. 1-33.

20. Robin V, Bernauer G, Akguen T, Heubrandtner T (2004) Spot weld performance under high strain rate loading conditions. Mathematical Modeling of Weld Phenomena.

21. Wang B, Lu G (2005) Dynamic Strength of Steel Welds under High Strain Rate Loading. Advanced Materials Research. 9: p. 87-92.

22. Cady CM, Chen SR, Gray GT (1996) Dynamic Materials Testing and Constitutive Modeling Of Structural Sheet Steel For automotive applications. Final Progress Report, in MST-5, MS-G755: Los Alamos NM.

23. Cady CM, Shuh Rong Chen, David A. Korzekwa, John F. Bingert,George, Gray T III ( 2000) Dynamic materials testing, texture, and yield-surface calculation of an automotive sheet steel. Metallurgical and Materials Transactions A. 31(10): p. 2439-2448.

24. Zhao H, Gary G (1996) The testing and behaviour modelling of sheet metals at strain rates from 10-4 to $104 \mathrm{~s}-1$. Materials Science and Engineering: A. 207(1): p. 46-50 
25. Dietenberger M, Buyuk M, Kan CD (2005) Development of a high strainrate dependent vehicle model. LS-Dyna Anwenderforum: Bamberg.

26. Khanna S (2001) Residual Stress Measurement in Spot Welds and the Effect of Fatigue Loading on Redistribution of Stresses Using High Sensitivity MoirÃ@ Interferometry. Journal of Engineering Materials and Technology. 123(1): p. 132.

27. Gray GT (2000) High-Strain-Rate Testing of Materials: The SplitHopkinson Pressure Bar in Methods in Materials Research. John Wiley \& Sons, Inc.

28. Gama BA, Lopatnikov SL, Gillespie JJW (2004) Hopkinson bar experimental technique: A critical review. Applied Mechanics Reviews. 57(4): p. 223-250.

29. Johnson GR, Cook WH (1983) A constitutive model and data for metals subjected to large strains, large strain rates and high temperatures," in In: Proceedings of the 7th International Symposium on Ballistics. The Hague, The Netherlands.

30. Johnson GR and Cook WH (1985) Fracture characteristics of three metals subjected to various strains, strain rates, temperatures and pressures. Engineering Fracture Mechanics. 21(1): p. 31-48.

31. Meyers MA (1994) Dynamic Behavior of Materials. New York: Wiley.

32. Haggag FM, Bell GEC (1992) Measurement of Yield Strength and Flow Properties In Spot Welds and Their HAZs at Various Strain Rates in ASM 3rd International Conference on Trends in Welding Research: Gatlinburg, Tennessee, USA.

33. Sarma A (2007) High strain properties of advanced high strength spot welded steels. University of Missouri-Columbia. 